\title{
Predictive value of procalcitonin for infection of patients with type- 2 diabetes mellitus
}

\author{
$\mathrm{XINSHUI} \mathrm{WANG}^{1^{*}}$, YANBEI SUN $^{2 *}$ and XIAONAN SHAO ${ }^{3}$ \\ Departments of ${ }^{1}$ Endocrinology, ${ }^{2}$ Nephrology and ${ }^{3}$ Nuclear Medicine, \\ The Third Affiliated Hospital of Soochow University, Changzhou, Jiangsu 213003, P.R. China
}

Received October 31, 2018; Accepted April 26, 2019

DOI: $10.3892 /$ etm.2019.7611

\begin{abstract}
The aim of the present study was to investigate the predictive value of procalcitonin (PCT) for infection in patients with type 2 diabetes mellitus (T2DM). A retrospective analysis of 178 patients with T2DM who were divided into non-infection, local infection and sepsis groups was conducted; in conjunction with 33 healthy control patients. Clinicopathological characteristics and inflammatory indicators were compared between the four groups. Patients in the non-infection group exhibited significantly higher PCT levels compared with healthy controls $(\mathrm{P}=0.002)$. In addition, PCT, C-reactive protein (CRP), white blood cell count and neutrophil percent were significantly different amongst patients with T2MD across different infection groups (all $\mathrm{P}<0.001$ ) with the following rank order: Sepsis group $>$ local infection group $>$ non-infection group (all $\mathrm{P}<0.05$ ). In addition, the following observations were made: i) PCT and CRP demonstrated larger areas under the curve (AUC) for predicting local infection (0.804 and 0.741, respectively); ii) PCT displayed lower sensitivity of only $21.8 \%$ at its classical cutoff value $(0.500 \mathrm{ng} / \mathrm{ml})$ whereas CRP exhibited higher sensitivity and specificity at 64.1 and $76.1 \%$, respectively, at its classical cutoff value (10.0 mg/l); and iii) PCT exhibited the largest AUC (0.914) for predicting sepsis with high sensitivity and specificity (86.4 and $84.5 \%$, respectively) at its cutoff value $(0.990 \mathrm{ng} / \mathrm{ml})$. Patients with T2DM without infection demonstrated higher baseline PCT levels. The present study clarified the value of PCT in predicting infection of T2DM patients. The application of PCT to predict local infection in patients with T2DM was identified to be inferior to CRP, but its ability to predict sepsis
\end{abstract}

Correspondence to: Dr Xiaonan Shao, Department of Nuclear Medicine, The Third Affiliated Hospital of Soochow University, 185 Juqian Road, Changzhou, Jiangsu 213003, P.R. China

E-mail: scorey@sina.com

*Contributed equally

Key words: type-2 diabetes mellitus, procalcitonin, c-reactive protein, infection, sepsis was concluded to be the best when compared with CRP, white blood cell count and neutrophil percent.

\section{Introduction}

Diabetes is a metabolic disease with a prevalence of $~ 9 \%$ worldwide according to the World Health Organization (1). Currently, 387 million people suffer from diabetes, with this number predicted to rise to $\sim 597$ million by 2035 (2). Previous studies have reported that diabetic patients are more susceptible to infection than non-diabetic patients. For example, Shah et al (3) confirmed that diabetic patients exhibited an increased prevalence of infections compared to the nondiabetic population with the highest incidence of osteomyelitis, pyelonephritis, cystitis, pneumonia, cellulitis, sepsis and peritonitis. Muller et al (4) also demonstrated that diabetic patients were more predisposed to lower respiratory tract infections, urinary tract infections, bacterial skin infections and mucous membrane infections than non-diabetic patients. In addition, Korbel et al (5) revealed that infection was the cause for $10 \%$ of emergency room visits among diabetic patients, and the incidence of infection in diabetic patients was two-fold higher than that of their non-diabetic counterparts. Hine et al (6) reported that almost all kinds of infections were common in diabetic patients, and bacterial, fungal or yeast infections were more prevalent in people with poor blood glucose control.

Precise prediction of infection and its severity in diabetic patients serves an important role in improving infection control and prognosis. At present, the 'gold standard' for the diagnosis of infections, in particular of blood infections, is by bacterial culture (7). However, the long testing period and poor sensitivity of bacterial culture used routinely in the clinic limits the standardized use of antibiotics. Therefore, it is necessary to identify useful predictive serum markers for infection in diabetic patients. C-reactive protein (CRP) has been regarded as an early indicator of infection or inflammation in addition to being a universal biomarker for numerous diseases and disorders such as myocardial infarction and neoplastic diseases (8). White blood count (WBC) and neutrophil percent (N\%) have also been traditionally used as markers for inflammation.

Procalcitonin (PCT) is the precursor of calcitonin and is secreted mainly by thyroidal parafollicularC-cells under normal conditions (9). However, during infection, PCT is ectopically secreted into the peripheral bloodstream by neuroendocrine 
cells of the liver, peripheral blood monocytes, macrophages, spleen, lung, small intestine and kidneys (10). Serum PCT levels increase rapidly as bacterial infection advances, but remain low during viral infections and non-specific inflammatory diseases such as ulcerative colitis (11). Until recently, changes in serum PCT levels of patients afflicted with type 2 diabetes mellitus (T2DM) following the onset of infection have not been well studied. Therefore, in the present study, the value of PCT for predicting infection in patients with T2DM was explored by comparing with different indicators of inflammation in patients with T2DM afflicted with different degrees of infection.

\section{Materials and methods}

General patient information. This study retrospectively analyzed 178 patients with T2DM (78 males; 100 females) at the Endocrinology Department of The Third Affiliated Hospital of Soochow University (Changzhou, China) between November 2013 and February 2017. The study was approved by the ethics committee of Soochow University (2019-WD-003) and patients signed informed consent forms. The patients in this study were between 22 and 95 years old with the average age of $62 \pm 16$ years, and a disease duration ranging between 1 day and 19 years since diagnosis. The inclusion criteria were patients with T2DM diagnosed according to the 1999 WHO diabetes diagnosis and classification criteria (12). Patients with type 1 diabetes, gestational diabetes and other rarer types of diabetes (e.g. genetic defects of beta-cell function) were excluded. Infection definition was based on the standardized criteria proposed by the Center for Disease Control and Prevention i.e. it already existed prior to hospitalization and was assessed based on disease history, symptoms, body temperature, etiological tests and improvement following antibiotics treatment. Sepsis was defined in accordance to the Sepsis-3 definitions of the Third International Consensus Definitions for Sepsis and Septic Shock (13). All patients were further classified into the non-infection (29 cases), local infection (125 cases) and sepsis groups ( 24 cases). In addition, 33 healthy individuals (19 males and 14 females) with an average age of $61 \pm 14$ years old who did not suffer from liver and kidney dysfunction or chronic diseases were included in the control group. Pregnant women, lactating women, patients receiving antibiotics within one week prior to admission and patients afflicted with acute complications from diabetes such as shock, autoimmune diseases, surgery, trauma, shock, severe liver and kidney dysfunction (glomerular filtration rate $<30 \mathrm{ml} / \mathrm{min}$ ), pancreatitis, cancer and blood system diseases were all excluded.

Observation indexes. The sex, age, body mass index (BMI), disease histories (including disease diagnosis, past history and personal history), comorbidities, infection sites and vital signs at admission in addition to the highest body temperature of the patients were recorded after admission. Blood samples were extracted from the patients within $24 \mathrm{~h}$ of admission prior to antibiotics treatment and used to measure inflammatory markers including WBC (normal range: 4-10x10 $/ 1$ ), N\% (normal range: 40-75\%), PCT (normal range: $0.021-0.500 \mathrm{ng} / \mathrm{ml}$ ) and CRP (normal range: $0-10.0 \mathrm{mg} / \mathrm{l}$ ). Complete blood count was examined using a Sysmex XN9000 hematology analyzer (Sysmex
Corporation). PCT was measured using a Roche Cobas 8000 modular analyzer (Roche Diagnostics). CRP was measured using a Beckman Coulter AU5800 chemistry analyzer (Beckman Coulter, Inc.). Blood culture was performed using the BD BACTEC FX blood culture system (BD Biosciences).

Statistical analysis. Data were analyzed using SPSS v15.0 (SPSS Inc.). The measurement of data with normal distribution and non-normal distribution were presented as the mean \pm standard deviation, and median and percentiles P50 (P25; P75), respectively. The count data were expressed as numbers or \%. Data exhibiting normal distribution were compared using independent-samples t-test or one-way analysis of variance followed by Student-Newman-Keuls post hoc test. Data demonstrating non-normal distribution were compared using Mann-Whitney U test and Kruskal-Wallis H test. Rates were compared using the $\chi^{2}$ test. The receiver operating characteristic (ROC) curves and the area under the curve (AUC) were used to compare the diagnostic efficacy of different indices. The sensitivity and specificity were calculated, and the cutoff value was determined by the Youden index. $\mathrm{P}<0.05$ was considered to indicate a statistically significant difference.

\section{Results}

Comparison of clinicopathological characteristics between patients with T2DM in the non-infection group and healthy controls. A comparison of clinicopathological characteristics between two groups is presented in Table I to illustrate the higher baseline inflammation index of patients with T2DM in the non-infection group compared with healthy controls. No significant differences were identified between the two groups in relation to average age, proportion of male, BMI, baseline CRP, WBC and N\% (all P>0.05; Table I; Fig. 1); however, patients with T2DM in the non-infection group exhibited significantly higher baseline PCT compared with the healthy controls $(\mathrm{P}=0.002)$.

Comparison of clinical characteristics and inflammatory indicators between patients with T2DM in non-infection, local infection and sepsis groups. Comparisons of clinicopathological characteristics and inflammatory indicators among patients with T2DM in the non-infection, local infection and sepsis groups are presented in Table II and Fig. 1. Age, male proportion, BMI and comorbidity proportion (hypertension, nephropathy and diabetic ketoacidosis (DKA) were not revealed to be significantly different across the three different groups (all P>0.05; Table II). However, patients in the sepsis group demonstrated a significantly higher proportion of urinary tract infections compared with patients in the local infection group (50.0 vs. $16.0 \%$, respectively; $\mathrm{P}<0.001$; Table II), whereas the proportions of other infections were not significantly different between the two groups (all P>0.05).

The blood levels of the four inflammatory markers tested (PCT, WBC, CRP and N\%) all exhibited significant differences between patients from the three infection groups (all $\mathrm{P}<0.001$; Table II; Fig. 1), ranking from high to low: Sepsis group $>$ local infection group $>$ non-infection group (all $\mathrm{P}<0.001$; Fig. 1).

ROC analysis of using different inflammatory indicators to predict patients with T2DM with local infection. ROC curves 
Table I. Comparison of clinicopathological characteristics between the non-infection group of patients with type 2 diabetes and healthy control group.

\begin{tabular}{|c|c|c|c|c|}
\hline Clinicopathological characteristic & Control $(n=33)$ & Non-infection $(n=29)$ & $\mathrm{Z} / \chi^{2} / \mathrm{t}$ & $\mathrm{P}$-value \\
\hline Age (years) & $61 \pm 14$ & $62 \pm 15$ & -0.182 & 0.857 \\
\hline Male (\%) & $19(57.6)$ & $12(41.4)$ & 1.620 & 0.203 \\
\hline $\mathrm{BMI}\left(\mathrm{kg} / \mathrm{m}^{2}\right)$ & $24.2 \pm 2.9$ & $24.5 \pm 4.0$ & 0.394 & 0.695 \\
\hline \multicolumn{5}{|l|}{ Clinical parameters } \\
\hline PCT (ng/ml) & $0.025(0.020 ; 0.032)$ & $0.034(0.025 ; 0.049)$ & -3.049 & 0.002 \\
\hline $\mathrm{CRP}(\mathrm{mg} / \mathrm{l})$ & $5.4(4.1 ; 7.1)$ & $6.5(4.2 ; 10.0)$ & -1.300 & 0.194 \\
\hline WBC $\left(\times 10^{9}\right.$ cells/l) & $5.61(5.07 ; 6.90)$ & $6.03(5.50 ; 8.06)$ & -1.086 & 0.086 \\
\hline $\mathrm{N} \%$ & $58.9(53.4 ; 63.2)$ & $62.1(55.2 ; 68.9)$ & -1.672 & 0.095 \\
\hline
\end{tabular}

Measurement of data with normal distribution and non-normal distribution were presented as the mean \pm standard deviation, and median and percentiles P50 (P25; P75), respectively. BMI, body mass index; CRP, C-reactive protein; N\%, neutrophil percent; PCT, procalcitonin; WBC, white blood cells.
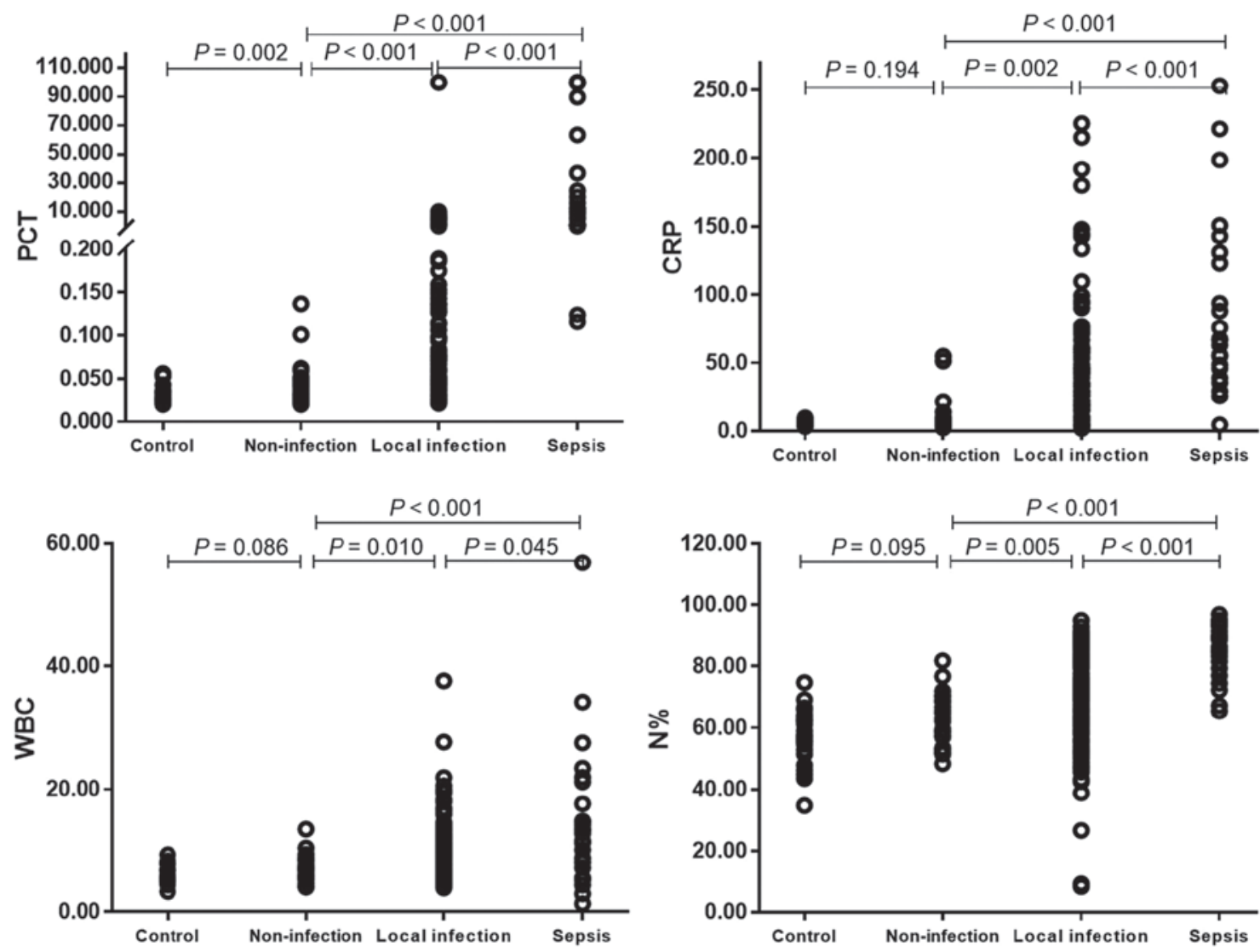

Figure 1. Comparisons of inflammatory indicators between the healthy control group and patients with type 2 diabetes mellitus in non-infection, local infection and sepsis groups. Patient in non-infection group had a higher baseline PCT level. As the severity of infection increased, the four inflammatory markers gradually increased. PCT, procalcitonin; CRP, C-reactive protein; N\%, neutrophil percent; WBC, white blood cells.

using PCT, CRP, WBC and N\% to predict local infection in patients with T2DM were analyzed (Fig. 2; Table III). The AUCs corresponding to PCT and CRP, which may be used to predict local infection of patients with T2DM, were demonstrated to be relatively higher $(0.804$ and 0.741 , respectively) compared with WBC and N\%. By contrast, the sensitivities of PCT, WBC and N\% were revealed to be very low, with values of $21.8,32.3$ and $41.8 \%$ at their classical cutoff points at $0.500,10.0$ and $75 \mathrm{ng} / \mathrm{ml}$, respectively (Table III). In comparison, the sensitivity of CRP was determined to be high, with a value of $64.1 \%$ at its classical cutoff point at $10.0 \mathrm{mg} / \mathrm{l}$, whereas its specificity was $76.1 \%$, compared with that of $100,91.3$ and $91.3 \%$ for PCT, WBC and N\% respectively. 
Table II. Comparison of clinicopathological characteristics and inflammatory markers among patients with type 2 diabetes in non-infection, local infection and sepsis groups.

\begin{tabular}{|c|c|c|c|c|c|}
\hline $\begin{array}{l}\text { Clinicopathological } \\
\text { characteristic }\end{array}$ & $\begin{array}{l}\text { Non-infection } \\
\quad(n=29)\end{array}$ & $\begin{array}{l}\text { Local infection } \\
\qquad(\mathrm{n}=125)\end{array}$ & $\begin{array}{l}\text { Sepsis } \\
(n=24)\end{array}$ & $\mathrm{F} / \chi^{2}$ & P-value \\
\hline Age (years) & $62 \pm 15$ & $62 \pm 17$ & $68 \pm 12$ & 1.876 & 0.156 \\
\hline Male (\%) & $12(41.4)$ & $60(48.0)$ & $6(25.0)$ & 4.410 & 0.110 \\
\hline BMI $\left(\mathrm{kg} / \mathrm{m}^{2}\right)$ & $24.5 \pm 4.0$ & $24.5 \pm 3.6$ & $22.7 \pm 3.5$ & 1.281 & 0.281 \\
\hline \multicolumn{6}{|l|}{ Comorbidities } \\
\hline Hypertension (\%) & $13(44.8)$ & $68(54.4)$ & $11(45.8)$ & 1.244 & 0.537 \\
\hline Nephropathy (\%) & $5(17.2)$ & $21(16.8)$ & $4(16.7)$ & 0.004 & 0.988 \\
\hline DKA $(\%)$ & $\mathrm{n} / \mathrm{a}$ & $17(13.6)$ & $1(4.2)$ & 0.916 & 0.339 \\
\hline \multicolumn{6}{|l|}{ Infection location } \\
\hline Respiratory tract $(\%)$ & $\mathrm{n} / \mathrm{a}$ & $61(48.8)$ & $7(29.2)$ & 3.128 & 0.077 \\
\hline Digestive tract (\%) & $\mathrm{n} / \mathrm{a}$ & $24(19.2)$ & $5(20.8)$ & 0.034 & 0.853 \\
\hline Urinary tract $(\%)$ & $\mathrm{n} / \mathrm{a}$ & $20(16.0)$ & $12(50.0)$ & 13.802 & $<0.001$ \\
\hline Skin $(\%)$ & $\mathrm{n} / \mathrm{a}$ & $24(19.2)$ & $3(12.5)$ & 0.241 & 0.623 \\
\hline Others $(\%)$ & $\mathrm{n} / \mathrm{a}$ & $21(16.8)$ & $3(12.5)$ & 0.049 & 0.825 \\
\hline \multicolumn{6}{|l|}{ Clinical parameters } \\
\hline PCT (ng/ml) & $0.034(0.025 ; 0.049)$ & $0.098(0.039 ; 0.413)$ & $10.205(1.085 ; 33.900)$ & 63.773 & $<0.001$ \\
\hline CRP (mg/l) & $6.5(4.2 ; 10.0)$ & $25.5(7.0 ; 52.9)$ & $67.1(44.2 ; 133.9)$ & 34.471 & $<0.001$ \\
\hline WBC $\left(\times 10^{9}\right.$ cells/l) & $6.03(5.50 ; 8.06)$ & $8.48(6.10 ; 10.96)$ & $13.04(7.48 ; 20.26)$ & 17.496 & $<0.001$ \\
\hline $\mathrm{N} \%$ & $62.1(55.2 ; 68.9)$ & $72.9(59.7 ; 82.4)$ & $88.8(79.9 ; 92.7)$ & 39.483 & $<0.001$ \\
\hline
\end{tabular}

Measurement of data with normal distribution and non-normal distribution were presented as the mean \pm standard deviation, and median and percentiles P50 (P25; P75), respectively. BMI, body mass index; CRP, C-reactive protein; DKA, diabetic ketoacidosis; N\%, neutrophil percent; n/a, not applicable; PCT, procalcitonin; WBC, white blood cells.

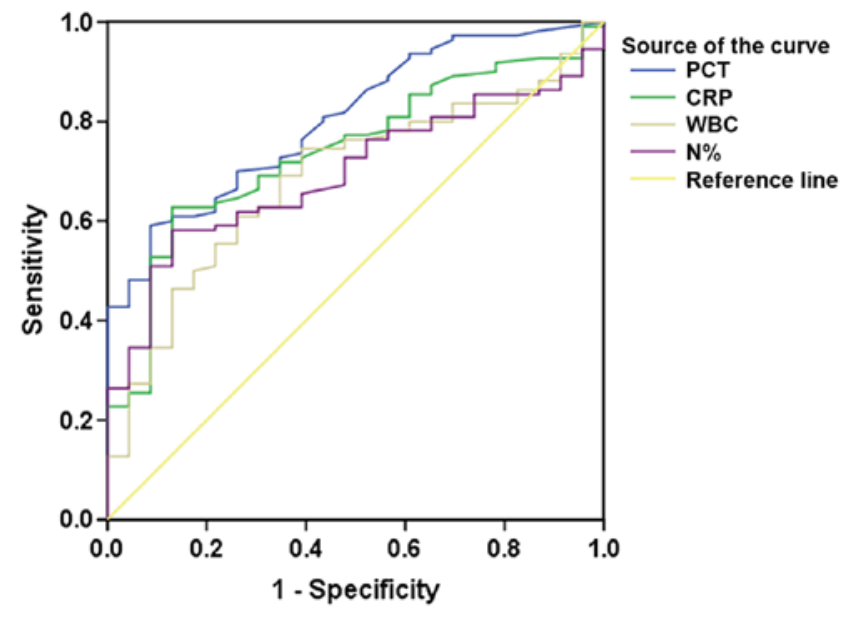

Figure 2. Receiver operating characteristic curves using PCT, CRP, WBC and $\mathrm{N} \%$ to predict local infection of patients with type 2 diabetes mellitus. AUCs of PCT and CRP were higher compared with WBC and N\% therefore, PCT and CRP had better diagnostic efficacy for local infection compared with WBC and N\%. PCT, procalcitonin; CRP, C-reactive protein; N\%, neutrophil percent; WBC, white blood cells; AUC, area under the curve.

ROC analysis of using different inflammatory indicators to predict sepsis in patients with T2DM. The ROC curves of using inflammatory indicators PCT, CRP, WBC and $\mathrm{N} \%$ to predict sepsis in patients with T2DM is presented in Fig. 3, and a summary of the ROC analyses is presented

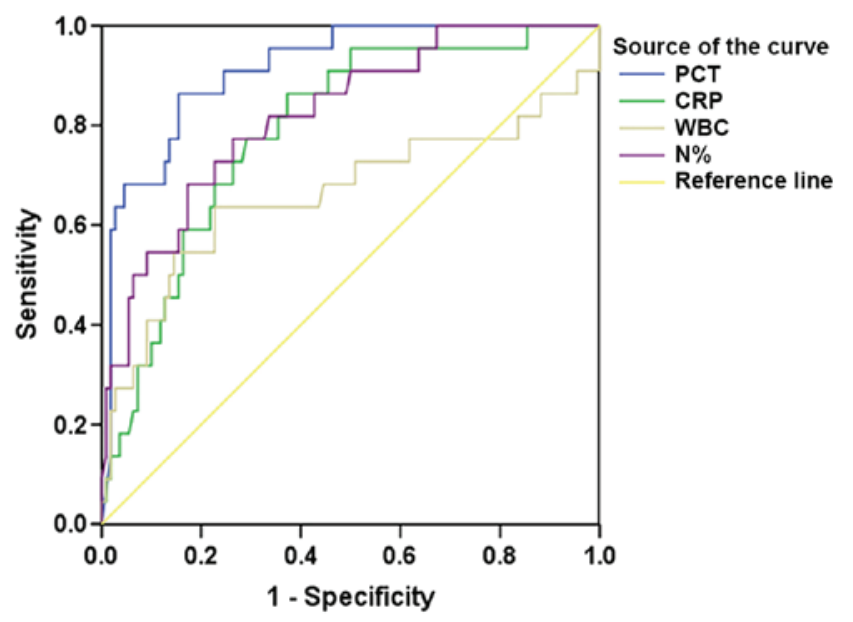

Figure 3. Receiver operating characteristic curves of using PCT, CRP, WBC and $\mathrm{N} \%$ to predict sepsis of patients with type 2 diabetes mellitus. PCT exhibited the largest AUC compared with the other three indexes therefore, PCT had better diagnostic efficacy for sepsis compared with CRP, WBC and $\mathrm{N} \%$. PCT, procalcitonin; CRP, C-reactive protein; N\%, neutrophil percent; WBC, white blood cells; AUC, area under the curve.

in Table IV. Of the four inflammatory indicators tested that could predict sepsis in patients with T2DM, PCT exhibited the largest AUC (0.914), the highest sensitivity $(86.4 \%)$ and the best specificity $(84.5 \%)$ with its cutoff value at $0.990 \mathrm{ng} / \mathrm{ml}$ (Table IV). 
Table III. A summary of receiver operating characteristic curve analysis using PCT, CRP, WBC and N\% to predict local infection in patients with type 2 diabetes.

\begin{tabular}{|c|c|c|c|c|c|c|}
\hline Indicator & AUC & P-value & $95 \% \mathrm{CI}$ & Cutoff $^{a}$ & Sensitivity $(\%)^{\mathrm{a}}$ & Specificity $(\%)$ \\
\hline \multirow[t]{2}{*}{ PCT } & 0.804 & $<0.001$ & $0.719-0.889$ & $0.046^{\mathrm{b}}$ & 70.0 & 73.9 \\
\hline & & & & $0.500^{b}$ & 21.8 & 100.0 \\
\hline \multirow[t]{2}{*}{ CRP } & 0.741 & $<0.001$ & $0.643-0.839$ & $8.2^{\mathrm{c}}$ & 69.1 & 69.6 \\
\hline & & & & $10.0^{c}$ & 64.1 & 76.1 \\
\hline \multirow[t]{2}{*}{ WBC } & 0.687 & 0.005 & $0.580-0.793$ & $7.41^{\mathrm{d}}$ & 60.9 & 73.9 \\
\hline & & & & $10.00^{\mathrm{d}}$ & 32.3 & 91.3 \\
\hline \multirow[t]{2}{*}{$\mathrm{N} \%$} & 0.696 & 0.003 & $0.601-0.791$ & $70.8^{\mathrm{e}}$ & 58.2 & 87.0 \\
\hline & & & & $75^{\mathrm{e}}$ & 41.8 & 91.3 \\
\hline
\end{tabular}

${ }^{\mathrm{a} B o l d}$ values denote the sensitivity and specificity at the classical cutoff. ${ }^{\mathrm{b}}$ Values are $\mathrm{ng} / \mathrm{ml} .{ }^{\mathrm{c}}$ Values are $\mathrm{mg} / \mathrm{l} .{ }^{\mathrm{d}}$ Values are $\mathrm{x} 10^{9} \mathrm{cells} / 1 .{ }^{\mathrm{e}} \mathrm{Values}$ are \%. AUC, area under the curve; CI, confidence interval; CRP, C-reactive protein; N\%, neutrophil percent; PCT, procalcitonin; WBC, white blood cells.

Table IV. A summary of receiver operating characteristic curve analysis using PCT, CRP, WBC and N\% to predict sepsis in patients with type 2 diabetes.

\begin{tabular}{lcccccc}
\hline Indicator & AUC & P-value & $95 \%$ CI & Cutoff & Sensitivity (\%) & Specificity (\%) \\
\hline PCT & 0.914 & $<0.001$ & $0.855-0.972$ & $0.990^{\mathrm{a}}$ & 86.4 & 84.5 \\
CRP & 0.790 & $<0.001$ & $0.694-0.886$ & $47.9^{\mathrm{b}}$ & 77.3 & 70.9 \\
WBC & 0.662 & 0.017 & $0.506-0.817$ & $11.15^{\mathrm{c}}$ & 63.6 & 77.3 \\
N\% & 0.822 & $<0.001$ & $0.728-0.916$ & $81.5^{\mathrm{d}}$ & 77.3 & 73.6
\end{tabular}

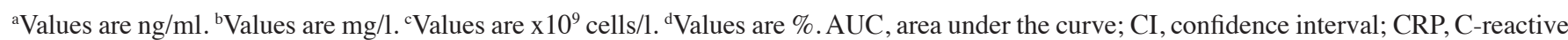
protein; N\%, neutrophil percent; PCT, procalcitonin; WBC, white blood cells.

\section{Discussion}

Results from the present study revealed that patients with T2DM in the non-infection group exhibited increased baseline PCT levels. Patients with T2DM are afflicted with chronic low-grade inflammation (14), hyperglycemia (15) and microvascular injury (16). These pathophysiological features of patients with T2DM could influence a variety of immune mechanisms and impair blood supply, thereby increasing the possibility of local infection. Patients with T2DM often have elevated blood glucose levels, significantly increased chance of blood coagulation and reduced neutrophil degranulation (17). Elevated glucose concentrations in the tissue surface layer will increase susceptibility to bacterial colonization and can potentially upregulate the expression of intercellular adhesion molecules and increase neutrophil adhesion, thereby impairing neutrophil chemotaxis and their subsequent antibacterial activities (18). Insulin resistance is a key feature of T2DM and can impact immune cell migration, oxidative explosion activity and phagocytosis (19). In addition, following macrophage-mediated stimulation, tissue cells, including adipocytes, will secrete PCT (20). PCT secretion is increased because adipose tissues harbor increased numbers of activated macrophages. Therefore, an increase in the baseline PCT levels of patients with T2DM may be associated with insulin resistance and various metabolic syndromes $(20,21)$.

Patients with chronic kidney disease are at high risk of severe infection (22-25). However, an insufficient number of studies have investigated the relationship between infection in diabetic patients and comorbid nephropathy and hypertension. Data from the present study revealed no difference in this relationship. Indeed, infection is a major predisposing factor for DKA. Azoulay et al (26) reported that the incidence of sepsis in patients with T2DM with DKA was not correlated, consistent with the results from the present study.

A previous study has reported that rare infectious diseases, including emphysematous pyelonephritis, invasive otitis externa, emphysematous cholecystitis and rhinocerebral mucormycosis were more prevalent in diabetic patients (27). In addition, diabetic patients appear to carry an increased likelihood of infection caused by certain strains of bacteria, including Staphylococcus aureus and Mycobacterium tuberculosis (27). There has also been evidence demonstrating that certain pathogens such as Streptococcus pneumoniae are associated with a higher rate of bacteremia (28). Data from the present study also suggested that local infection occurred mostly at the respiratory tract (48.8\%), and the rate of urinary tract infection was significantly higher in patients with sepsis compared with patients with local infection (50.0 vs. $16.0 \%)$. 
This may be related to the high proportion of females in the sepsis group as they are more susceptible to urinary tract infections (29).

A number of studies have suggested that PCT could be used as an indicator to exclude bacterial infections because it could reliably and accurately reduce inappropriate antibiotic exposure compared with the traditional tests, including CRP and WBC (30-33). The present study demonstrated that PCT and CRP may be used to predict local infection, but the former exhibited lower sensitivity than the latter. This may be because the sensitivity of PCT to predict local infection is reduced due to the increased baseline PCT levels in patients with T2DM, whereas T2DM exerted smaller effects on CRP. Alternatively, leukocytes have been reported to be a potential source of PCT during sepsis (34); and since local infection results in reduced specific leukocyte stimulation, PCT was only slightly increased.

PCT levels are almost undetectable in healthy subjects, but it could be detected within $2 \mathbf{h}$ of common bacterial infection and it increases rapidly within $6 \mathrm{~h}$ before peaking at about $24 \mathrm{~h}$ (35). Therefore, measuring PCT levels in the blood enables the early diagnosis and warning of sepsis $(36,37)$. Davies et al (38) proposed that PCT was the most effective biomarker in the diagnosis of sepsis and was superior to CRP. A number of studies have reported that unlike CRP levels, which did not increase significantly with the progression of disease, PCT levels increased significantly in patients with severe organ dysfunction, sepsis and septic shock $(31,39)$, possibly due to CRP and PCT of diverse origins in the inflammatory process. CRP is an acute phase reactant protein synthesized by the liver, and is considered to be a superior diagnostic indicator of early inflammation (40). During severe infection, CRP levels in patients with liver dysfunction did not increase further (34), thus reducing its diagnostic efficacy. The present study demonstrated that PCT was superior to CRP and other inflammatory indicators for the prediction of sepsis, consistent with the studies aforementioned.

The present study contains a number of limitations. Firstly, owing to its retrospective design, the inclusion cases may contain a degree of selective bias. Secondly, bacterial and non-bacterial infections were not distinguished in this study due to the reduced proportion of microbiologically confirmed infection, which may also affect the evaluation of PCT as a diagnostic marker for infection.

In summary, the present findings identified that the baseline PCT levels increased significantly in patients with T2DM without infection. Furthermore, the value of PCT for the prediction of infection in T2DM patients was clarified. The application of PCT to predict local infection in patients with T2DM was inferior to CRP, but its ability to predict sepsis was concluded to be superior compared with CRP, WBC and N\%.

\section{Acknowledgements}

Not applicable.

\section{Funding}

The present study was supported by The Science and Technology Planning Project of Changzhou (grant no. CJ20180022).

\section{Availability of data and materials}

The datasets used during the present study are available from the corresponding author upon reasonable request.

\section{Authors' contributions}

XW, YS and XS designed the study. XW and YS performed the experiments. XS analyzed the data. XW and XS interpreted the data and provided discussion of the results. XW wrote the manuscript and YS revised it with XS. All authors read and approved the final version of the manuscript for publication.

\section{Ethics approval and consent to participate}

The study was approved by the ethics committee of Soochow University (2019-WD-003) and all patients signed informed consent forms.

\section{Patient consent for publication}

Not applicable.

\section{Competing interests}

The authors declare that they have no competing interests.

\section{References}

1. Whiting DR, Guariguata L, Weil C and Shaw J: IDF diabetes atlas: Global estimates of the prevalence of diabetes for 2011 and 2030. Diabetes Res Clin Pract 94: 311-321, 2011.

2. Rahelic D: 7th edition of IDF Diabetes Atlas-call for Immediate Action. Lijec Vjesn 138: 57-58, 2016 (In Croatian).

3. Shah BR and Hux JE: Quantifying the risk of infectious diseases for people with diabetes. Diabetes Care 26: 510-513, 2003.

4. Muller LM, Gorter KJ, Hak E, Goudzwaard WL, Schellevis FG, Hoepelman AI and Rutten GE: Increased risk of common infections in patients with type 1 and type 2 diabetes mellitus. Clin Infect Dis 41: 281-288, 2005.

5. Korbel L and Spencer JD: Diabetes mellitus and infection: An evaluation of hospital utilization and management costs in the United States. J Diabetes Complicat 29: 192-195, 2015.

6. Hine JL, de Lusignan S, Burleigh D, Pathirannehelage S, McGovern A, Gatenby P, Jones S, Jiang D, Williams J, Elliot AJ, et al: Association between glycaemic control and common infections in people with Type 2 diabetes: A cohort study. Diabetic Med 34: 551-557, 2017.

7. Florio W, Morici P, Ghelardi E, Barnini S and Lupetti A: Recent advances in the microbiological diagnosis of bloodstream infections. Crit Rev Microbiol 44: 351-370, 2018.

8. Vashist SK, Venkatesh AG, Marion Schneider E, Beaudoin C, Luppa PB and Luong JH: Bioanalytical advances in assays for C-reactive protein. Biotechnol Adv 34: 272-290, 2016.

9. Muller B and Becker KL: Procalcitonin: How a hormone became a marker and mediator of sepsis. Swiss Med Wkly 131: 595-602, 2001.

10. Karzai W, Oberhoffer M, Meier-Hellmann A and Reinhart K: Procalcitonin-a new indicator of the systemic response to severe infections. Infect 25: 329-334, 1997.

11. Snider RH Jr, Nylen ES and Becker KL: Procalcitonin and its component peptides in systemic inflammation: immunochemical characterization. J Invest Med 45: 552-560, 1997.

12. Alberti KG and Zimmet PZ: Definition, diagnosis and classification of diabetes mellitus and its complications. Part 1: Diagnosis and classification of diabetes mellitus provisional report of a WHO consultation. Diabet Med 15: 539-553, 1998. 
13. Levy MM, Fink MP, Marshall JC, Abraham E, Angus D, Cook D, Cohen J, Opal SM, Vincent JL and Ramsay G: 2001 SCCM/ESICM/ACCP/ATS/SIS International Sepsis Definitions Conference. Intensive Care Med 29: 530-538, 2003.

14. Wellen KE and Hotamisligil GS: Inflammation, stress, and diabetes. J Clin Invest 115: 1111-1119, 2005.

15. Jafar N, Edriss $\mathbf{H}$ and Nugent $\mathbf{K}$ : The effect of short-term hyperglycemia on the innate immune system. Am J Med Sci 351: 201-211, 2016.

16. Barrett EJ, Liu Z, Khamaisi M, King GL, Klein R, Klein BEK, Hughes TM, Craft S, Freedman BI, Bowden DW, et al: Diabetic Microvascular Disease: An Endocrine Society Scientific Statement. J Clin Endocrinol Metab 102: 4343-4410, 2017.

17. Stegenga ME, van der Crabben SN, Blumer RM, Levi M, Meijers JC, Serlie MJ, Tanck MW, Sauerwein HP and van der Poll T: Hyperglycemia enhances coagulation and reduces neutrophil degranulation, whereas hyperinsulinemia inhibits fibrinolysis during human endotoxemia. Blood 112: 82-89, 2008.

18. Morigi M, Angioletti S, Imberti B, Donadelli R, Micheletti G, Figliuzzi M, Remuzzi A, Zoja C and Remuzzi G: Leukocyteendothelial interaction is augmented by high glucose concentrations and hyperglycemia in a NF- $\mathrm{B}$-dependent fashion. J Clin Invest 101: 1905-1915, 1998

19. Cohen G, Ilic D, Raupachova J and Horl WH: Resistin inhibits essential functions of polymorphonuclear leukocytes. J Immunol 181: 3761-3768, 2008

20. Becker KL, Nylen ES, White JC, Muller B and Snider RH Jr: Clinical review 167: Procalcitonin and the calcitonin gene family of peptides in inflammation, infection, and sepsis: A journey from calcitonin back to its precursors. J Clin Endocrinol Metab 89: $1512-1525,2004$

21. Abbasi A, Corpeleijn E, Postmus D, Gansevoort RT, de Jong PE, Gans RO, Struck J, Hillege HL, Stolk RP, Navis G and Bakker SJ: Plasma procalcitonin is associated with obesity, insulin resistance, and the metabolic syndrome. J Clin Endocrinol Metab 95: E26-E31, 2010.

22. James MT, Quan H, Tonelli M, Manns BJ, Faris P, Laupland KB and Hemmelgarn BR: CKD and risk of hospitalization and death with pneumonia. Am J Kidney Dis 54: 24-32, 2009.

23. James MT, Laupland KB, Tonelli M, Manns BJ, Culleton BF and Hemmelgarn BR: Risk of bloodstream infection in patients with chronic kidney disease not treated with dialysis. Arch Inter Med 168: 2333-2339, 2008.

24. Davenport A: Peritonitis remains the major clinical complication of peritoneal dialysis: The London, UK, peritonitis audit 2002-2003. Perit Dial Int 29: 297-302, 2009.

25. Mactier R: Peritonitis is still the achilles' heel of peritoneal dialysis. Perit Dial Int 29: 262-266, 2009.
26. Azoulay E, Chevret S, Didier J, Barboteu M, Bornstain C, Darmon M, Le Gall JR, Vexiau P and Schlemmer B: Infection as a trigger of diabetic ketoacidosis in intensive care-unit patients. Clin Infect Dis 32: 30-35, 2001

27. Joshi N, Caputo GM, Weitekamp MR and Karchmer AW: Infections in patients with diabetes mellitus. New Engl J Med 341: 1906-1912, 1999.

28. Marrie TJ: Bacteraemic pneumococcal pneumonia: A continuously evolving disease. J Infect 24: 247-255, 1992.

29. Nichols GA, Brodovicz KG, Kimes TM, Deruaz-Luyet A and Bartels DB: Prevalence and incidence of urinary tract and genital infections among patients with and without type 2 diabetes. J Diabetes Complications 31: 1587-1591, 2017.

30. Luzzani A, Polati E, Dorizzi R, Rungatscher A, Pavan R and Merlini A: Comparison of procalcitonin and C-reactive protein as markers of sepsis. Crit Care Med 31: 1737-1741, 2003.

31. Castelli GP, Pognani C, Meisner M, Stuani A, Bellomi D and Sgarbi L: Procalcitonin and C-reactive protein during systemic inflammatory response syndrome, sepsis and organ dysfunction. Crit Care 8: R234-R242, 2004

32. Schuetz P, Albrich W, Christ-Crain M, Chastre J and Mueller B: Procalcitonin for guidance of antibiotic therapy. Expert Rev Anti Infect Ther 8: 575-587, 2010.

33. Lee SH, Chan RC, Wu JY, Chen HW, Chang SS and Lee CC: Diagnostic value of procalcitonin for bacterial infection in elderly patients-a systemic review and meta-analysis. Int J Clin Pract 67: 1350-1357, 2013.

34. Park JH, Kim DH, Jang HR, Kim MJ, Jung SH, Lee JE, Huh W, Kim YG, Kim DJ and Oh HY: Clinical relevance of procalcitonin and C-reactive protein as infection markers in renal impairment: A cross-sectional study. Crit Care 18: 640, 2014.

35. Brechot N, Hekimian G, Chastre J and Luyt CE: Procalcitonin to guide antibiotic therapy in the ICU. Int J Antimicrob Agents 46: S19-S24, 2015

36. Tan BH, Png ME, Yeo CP and Wong GC: Procalcitonin in febrile neutropenia-timing is important. Support Care Cancer 22: 583-584, 2014.

37. Bodmann KF, Schenker M, Heinlein W and Wilke MH: Procalcitonin as a tool for the assessment of successful therapy of severe sepsis: An analysis using clinical routine data. Med Klin Intensivmed Notfmed 113: 533-541, 2016.

38. Davies J: Procalcitonin. J Clin Pathol 68: 675-679, 2015

39. Claeys R, Vinken S, Spapen H, ver Elst K, Decochez K, Huyghens L and Gorus FK: Plasma procalcitonin and C-reactive protein in acute septic shock: Clinical and biological correlates. Crit Care Med 30: 757-762, 2002.

40. Sierra R, Rello J, Bailen MA, Benitez E, Gordillo A, Leon C and Pedraza S: C-reactive protein used as an early indicator of infection in patients with systemic inflammatory response syndrome. Intens Care Med 30: 2038-2045, 2004. 